\title{
CUSTOM MADE INTERNAL AND EXTERNAL NASAL SPLINTS : A COST EFFECTIVE ALTERNATIVE
}

\author{
Sheikh Saadat Ullah Waleem, Muhammad Waqas Ayub, Manzoor Ahmad*, Shahzad Maqbool**, Maqbool Raza***, Ejaz Rahim*** \\ Combined Military Hospital Kohat/National University of Medical Sciences (NUMS) Pakistan, ${ }^{*}$ Combined Military Hospital Dera Ismail Khan/National \\ University of Medical Sciences (NUMS) Pakistan, ** Pak Emirates Military Hospital /National University of Medical Sciences (NUMS) Pakistan, \\ ${ }^{* * *}$ Combined Military Hospital Multan/National University of Medical Sciences (NUMS) Pakistan
}

\begin{abstract}
Objectives: To evaluate the usability and effectiveness of tailor made internal and external nasal splints after nasal surgery. Study Design: An observational study.

Place and Duration of Study: Combined Military Hospital Kohat, from Nov 2015 to Aug 2017.

Methodology: the study was carried out on 523 patients who underwent nasal surgery by the same team of surgeons. Custom made free of cost internal and external nasal splints were used as required. Complications pertaining to the use of nasal splints were recorded.

Results: The custom made splints were found to be an excellent and cost effective alternative of commercially available expensive splints. The benefits and pitfalls were comparable.

Conclusion: Where these free of cost splints does the job they as well save a lot of money and can be used as an effective alternative to commercially available splints.
\end{abstract}

Keywords: Intravenous infusion splints, Nasal surgery, Nasal splints.

How to Cite This Article: Waleem SSU, Ayub MW, Ahmad M, Mabool S, Raza M, Rahim E. Custom Made Internal and External Nasal Splints: A Cost Effective Alternative. Pak Armed Forces Med J 2021; 71 (Suppl-3): S577-580. Doi: https://doi.org/10.51253/pafmj.v1i1.7946

This is an Open Access article distributed under the terms of the Creative Commons Attribution License (https://creativecommons.org/licenses/by-nc/4.0/), which permits unrestricted use, distribution, and reproduction in any medium, provided the original work is properly cited.

\section{INTRODUCTION}

Deflected nasal septum, hypertrophic inferior turbinates and nasal polypi are the most common causes of nasal obstruction often requiring surgical intervention in the form of Submucoperichondrial resection, Septoplasty, Partial inferior turbinectomy or Intranasal polypectomy. Sometimes these procedures are done alone whereas most of the times they are done in combination. In the recent years internal nasal splints are being used more and more during these surgeries as they not only reduce the time for which the postoperative nasal packing have to be retained but also significantly reduce the incidence of complications like septal haematoma, septal abscess, septal perforation and synechiae formation. ${ }^{1}$ In many cases use of nasal splints have alleviated the need for post operative nasal packs thereby reducing considerable morbidity. ${ }^{2}$

In addition external splinatage of the nasal bony framework is often required after manipulating and reducing fractures of the nasal bones. ${ }^{3}$ It is also routinely carried out as a final and essential step of Cosmetic Rhinoplasty. ${ }^{4}$

Many commercially available nasal splints, both for use inside as well as outside of the nose are avail-

Correspondence: Dr Sheikh Saadat Ullah Waleem, Classified ENT Specialist, Combined Military Hospital Kohat-Pakistan able in the market. Those available for use inside the nose range from PKR 1200-4000 whereas external nasal splints range from PKR 1500-5000. We, being a developing country are always hard pressed for funds to run our hospitals and rationalization always helps to spend this hard procured funds in the best possible place for the best possible outcome for the ailing. In view of this we devised our own internal and external nasal splints that come free of cost and serves the purpose well without any significant drawback (Figure-1). The experience is being shared in this article.

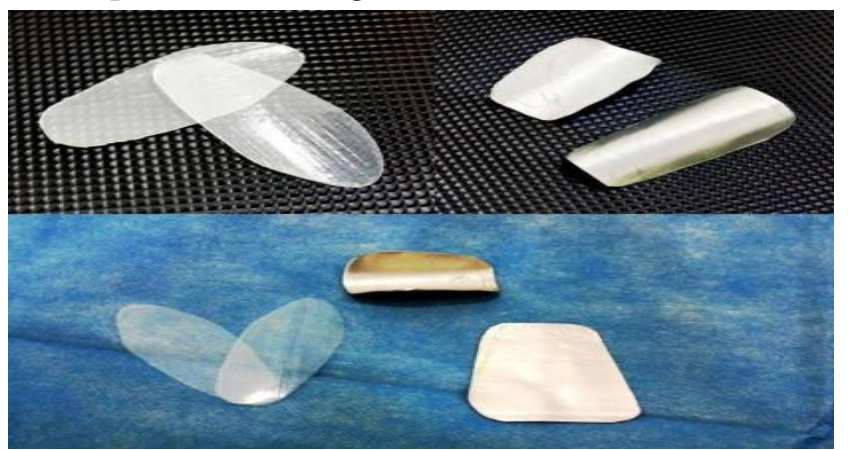

Figure-1: Custom made free of cost internal and external nasal splints.

\section{METHODOLOGY}

This observational study was carried out at the ENT Department, Combined Military Hospital, Kohat Cantt, from November 2015 to August 2017. 
Inclusion Criteria: All nasal surgeries requiring postoperative internal or external nasal splinting were included.

Exlclusion Criteria: Nasal surgeries that didn't require internal or external nasal splinting were excluded. all patients who failed to follow up for a minimum of 4 weeks were excluded.

A total of 523 such surgeries were performed during this period. It included surgeries performed under local as well as general anesthesia. The patients ages ranged from 8-65 years. Both sexes were included.

Internal splints were tailored out of used IV drips plastic bottles. The upper and lower hard portions of drips were discarded. Only the middle soft portion was used. The soft part of the drips that were to be used were cut into square sheets of $10 \mathrm{~cm} \times 6 \mathrm{~cm}$. Two such sheets could be easily cut out of the soft portion of a $1000 \mathrm{ml}$ drip. It was cleaned of any paper/label by soaking in boiled water for a few minutes. It was then dipped in sterilizer solution (Cidex ortho-phthaladehyde or similar solution) for appropriate period of time at appropriate temperature as per recommendation given in the supplier manual of these solutions. These sheets were then kept in a sterilized box and time and date was marked. These were used within the next 24-72 hours and rest of the sheets were discarded or sterilized again. When required, a single sheet is taken out of the sterilized box and aseptically shifted to the surgical trolley. It was then cut into custom sizes as required during the surgery. A single sheet was sufficient to cut out 2 splints one for each side of the septum (Figure-2). These splints were well lubricated with medicated ointment before insertion and secured to the septum with the help of a trans septal single silk suture with long cut ends. Patients were instructed and educated regarding effective nasal douches and use of ample amount of medicated ointment postoperatively. This could start off after a few hours of surgery when nasal packs were not used or right after removal of the nasal packs. The splints were removed after 7-10 days under topical anesthesia after removal of silk stitch.

External nasal splints were made out of tin containers of paraffin gauze dressing. The tin is soft and malleable yet hard enough to support the nasal framework as a splint. Both the lid and the container can be used. After the gauze dressing has been used up the tins are kept and cleaned with a dry gauze piece. Using a pair of heavy scissors the sides are cut off so that the central squares of tin are obtained. Two such pieces can be obtained from each tin, one from the upper and lower parts each (Figure-3). Each square is then folded onto itself to make a rectangle, hammered together and then cut into two equal squares. This gives us 4 such squares from each tin however since it is all for free any size required can be obtained. These are then boiled in the sterilizer and later put in the sterilizing solution for appropriate time at appropriate temperature and then shifted to and kept in a sterilized box under aseptic conditions. It can then be cut into the desired shape and size when required using a pair of heavy scissors. Special care is taken to avoid any sharp edges while cutting out the final product. These external nasal splints are applied over steristrips and a thin sheet of cotton padding and kept in place with the help of additional surgical tape (Figure-4).

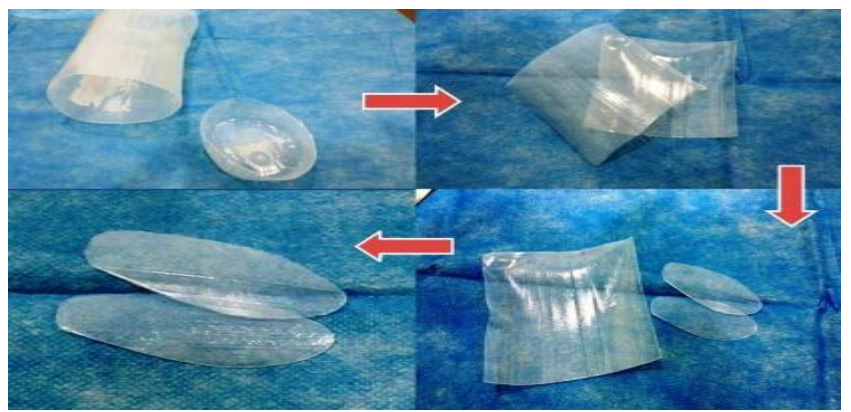

Figure-2: Empty Intravenous drip is being utilized to cut out tailor made internal splints.

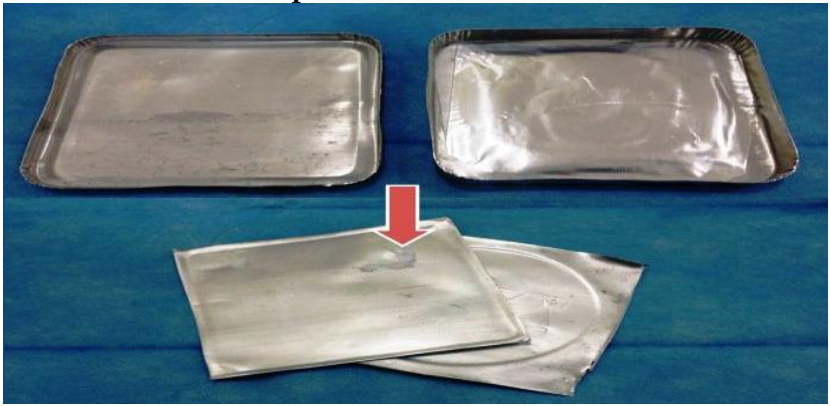

Figure-3: Empty Vaseline gauze tin is cleaned and cut to obtain 2 squares of tin.

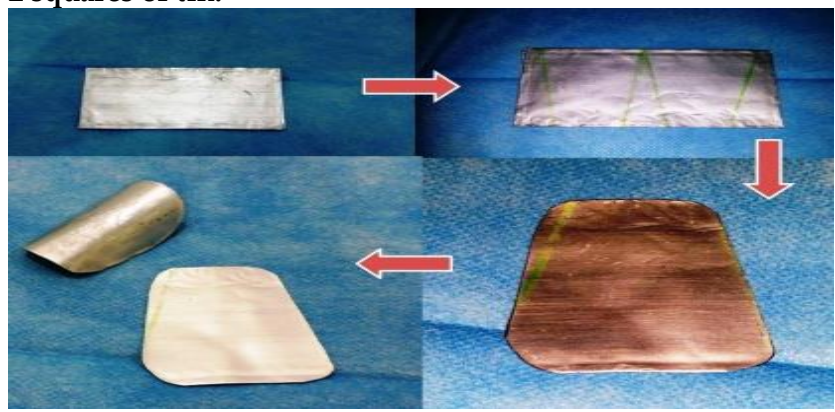

Figure-4: The tin square is folded into a rectangle and hammered to give it strength and the desired size of splint is marked and cut out.

These custom made splints (internal as well as external) were used and patients were followed up for 
development of adhesions, septal perforation, septal or skin ulceration, septal haematoma, septal abscess and/ or any other complication related to the use of these or comparative commercially available splints. All patients were followed up for 4 weeks postoperatively.

\section{RESULTS}

A total of 523 nasal surgeries were carried out in which custom made splints were used. Different types of complications of nasal surgeries in the presence of custom made nasal splints were noted and compared with other studies charting out the prevention of complications where commercial nasal splints were used. Major chunk of the surgeries 211 (40.34\%) was Submucoperichondrial resection or Septoplasty alone carried out under local anesthesia. Partial Inferior Linear Turbinectomy was carried out in 131 (25.04\%) of cases. Tailor made External Nasal splints were mainly used in Cosmetic Rhinoplasties 64 (12.23\%). Breakdown of surgeries is given in Table-I. In 9 cases recurrence of septal deviation was noted which accounted to $1.72 \%$, whereas iatrogenic septal perforation was noted in only $0.57 \%$ of cases. None of the cases developed septal haematoma, septal abscess or septal adhesions. None of the cases where tailor made external splints were used developed skin ulceration/necrosis nor malunion/displaced nasal bones. Efficacy of custom made nasal splints in the prevention of complications of nasal surgery was found to be comparable with those of commercially available expensive nasal splints. Complications encountered while using these splints (Table-II).

Table-I: Breakdown of Surgeries.

\begin{tabular}{l|c}
\hline Type of Surgery & $\begin{array}{c}\text { No. of Cases } \\
\mathbf{n}(\mathbf{\%})\end{array}$ \\
\hline Septoplasty/Submucoperichondrial resection & $211(40.34)$ \\
\hline Septoplasty \pm Partial Inferior Turbinectomy & $131(25.04)$ \\
\hline Cosmetic Rhinoplasty & $64(12.23)$ \\
\hline Turbinectomy alone & $59(11.28)$ \\
\hline Fracture Nasal bones & $26(04.97)$ \\
\hline Polypectomy alone & $19(03.63)$ \\
\hline Polypectomy \pm Septoplasty \pm Turbinectomy & $13(02.48)$ \\
\hline Total & $523(100)$ \\
\hline $\begin{array}{l}\text { Table-II: Complications of nasal surgery while using custon } \\
\text { made nasal splints. }\end{array}$ \\
\hline Complication Types & Complications n (\%) \\
\hline Recurrence of septal deviation & $9(1.72 \%)$ \\
\hline Septal Perforation & $3(0.57 \%)$ \\
\hline Septal Haematoma & $-(-)$ \\
\hline Septal abscess & $-(-)$ \\
\hline Synechiae / Adhesions & $-(-)$ \\
\hline Displaced Nasal Bones & $-(-)$ \\
\hline Skin Excoriation/Ulceration/Necrosis & $-(-)$ \\
\hline Septal Granulations & $5(0.95 \%)$ \\
\hline Toxic Shock Syndrome & $-(-)$ \\
\hline
\end{tabular}

\section{DISCUSSION}

Use of intranasal splints by ENT surgeons is on the rise mainly because of their many advantages. There are many studies that emphasize upon their role in reducing post operative bleeding, prevention of residual deformity and synechiae formation, decreased incidence of postoperative pain and haematoma formation. 5,6

Complications of nasal surgeries encountered while using these custom made nasal splints were compared to complications quoted in other international and national studies where no splints were used or commercially available splints were used. ${ }^{7}$ The most common problem encountered after septal surgery was recurrence of septal deviation or residual septal deviation. It was seen only in $01.72 \%$ of cases which is comparable with the work of Wadhera et al who reported $6.7 \%$ recurrence. ${ }^{8,9}$ It was noted that the relatively harder splints actually helped in keeping the residual septal cartilage in the midline during the postoperative period, thereby minimizing the chances of an inadequate septal correction. A similar effect was noted in prevention of formation of a septal haematoma as not a single case of postoperative septal hematoma formation was noted since the plastic splints keep the two mucoperichondrial-periosteal flaps together. This is comparable to any other type of splints, plastic or sialastic. It was further noted that not a single postoperative case of adhesions formation was seen. ${ }^{10}$ The splints act as an effective barrier to the formation of adhesions between the medial and lateral walls of nose during the recovery phase. ${ }^{11}$ This is again comparable to other studies where sialastic splints have been used. ${ }_{12,13}$ Though a unilateral or many a times a bilateral different level flap tear was not very rare during elevation of mucoperichondrial-periosteal flap raising or spur gouging the splints provided an effective scafold over which the flaps could heal effectively thereby reducing the incidence of a septal perforation. Only 3 cases $(0.57 \%)$ of septal perforations were noted. This again is comparable to any type of expensive commercially available splint type. ${ }^{14,15}$

A relatively newer finding was formation of small granulations along the anterior end of the tailor made splint in $0.95 \%$ of the cases. It was most likely due to a relatively loose septal stitch that allowed the splints to move and rub against the septal mucosa resulting in formation of reactive granulations at that spot. It never resulted in any troublesome bleeding and resolved after removal of splints in due time and with ample 


\section{Custom Made Internal and External Nasal Splints}

use of intranasal medicated ointment. In not a single patient splints were required to be removed before 7 10 days because of any reason let it be postoperative pain, infection or bleeding.

Tin made external nasal splints were found to be equally effective compared to their commercially available expensive counterparts.15,16 Another relatively cheaper choice is to use splints cut out of Plaster of Paris (POP), however the time required to cut this splint out at the end of a long surgery from layered POP bandages and then letting it set after application as it dries up is much more as compared to simply using a pair of heavy scissors and cutting the required size out of a tin and placing and securing it. Moreover once the POP gets set there is no room to accommodate any postoperative swelling that may set in later and this may result in damage to the nasal skin in the form of necrosis. ${ }^{17,18}$ Tin splint on the other hand is relatively flexible. Where it is rigid enough to support the nasal bony framework in its newly placed position it still has flexibility enough to allow a bit of post operative swelling without causing any skin necrosis. Not a single case of skin damage or bone displacement was noted and the splints cut out of gauze tin was found to be very handy and effective.

It is worth mentioning here that by using these tailor made splints we were able to save our hospital or our patients a total sum of PKR 1307500 (considering price of internal nasal splints to be PKR 2500) in lieu of internal nasal splints and PKR 225000 (considering price of external nasal splint to be PKR 2500) in lieu of external nasal splints during the time period of less than 2 years.

\section{RECOMMENDATION}

Further comparative studies are recommended.

\section{CONCLUSION}

These tailor made nasal splints are readily available at no cost and were found to be equally effective as compared to their expensive commercially marketed counterparts. These not only effectively do the job that is required out of them but at the same time save a lot of hospital resources.

Conflict of Interest: None.

\section{Authors' Contribution}

SSUW: Direct contribution, MWA: Intellectual contribution, MA: Intellectual contribution, SM: Intellectual contribution, MR: Intellectual contribution, ER: Intellectual contribution.

\section{REFERENCES}

1. Kiran Naik. A novel way of trans-septal splint suturing without nasal packing for septoplasty. Indian J Otolaryngol Head Neck Surg 2015; 67(1): 48-50.

2. Dubin MR, Pletcher SD. Postoperative packing after septoplasty: is it necessary?. Otolaryngol Clin North Am 2009; 42(2): 279-285.

3. Higuera S, Lee EI, Cole P, Hollier LH Jr, Stal S. Nasal trauma and the deviated nose. Plast Reconstr Surg 2007; 120(Supp- 2): 64S$75 S$.

4. Payam Varedi, Behnam Bohluli. Do the size and extension of the external nasal splint have an effect on the osteotomy, brow lines, and long-term results of rhinoplasty: a prospective randomized controlled trial of 2 methods. J Oral Maxillofacial Surg 2015; 73(9): 1843.e1-1843.e9.

5. Deniz M, Ciftçi Z, Işık A, Demirel OB, Gültekin E. The impact of different nasal packings on postoperative complications. Am J Otolaryngol 2014; 35(5): 554-557.

6. Karatas A, Pehlivanoglu F, ,Salviz M, Kuvat N, Cebi IT, Dikmen $B$, et al. The effects of the time of intranasal splinting on bacterial colonization, postoperative complications, and patient discomfort after septoplasty operations. Braz J Otorhinolaryngol 2016; 82(6): 654-661.

7. Muhammad IA, Rahman N. Complications of the surgery for deviated nasal septum. J Coll Physicians Surg Pak 2003; 13(10): 565-568.

8. Allareddy, V, Allareddy, V, Nalliah, RP. Epidemiology of facial fracture injuries. J Oral Maxillofac Surg 2011; 69(1): 26132618.

9. Wadhera R1, Zafar N, Gulati SP, Kalra V, Ghai A. Comparative study of intranasal septal splints and nasal packs in patients undergoing nasal septal surgery. Ear Nose Throat J 2014; 93(9): 396-408.

10. Mahmood K, Baig MN, Ayub N, Aziz T. Efficacy of nasal splints in reducing the incidence of intranasal adhesions following septoplasty. J Islamic Int Med Coll 2016; 11(1): 8-10.

11. Osama GA, Khalf A. H. The Value of intranasal splints after partial inferior turbinectomy. Indian J Otolaryngol Head Neck Surg 2015; 67(1): 75-80.

12. Jung YG, Hong JW, Eun YG, Kim MG. Objective usefulness of thin silastic septal splints after septal surgery. Am J Rhinol Allerg 2011; 25(3): 182-185.

13. Iqbal H, Farooqi TH. The effects of intranasal splints in septal surgery. Pak J Med Health Sci 2010; 4(3): 290-291.

14. Drezner DA . Thermoplastic splint for use after nasal fracture. Otolaryngol Head Neck Surg 1994; 111(1): 146-147.

15. Jayakumar NK, Rathnaprabhu V, Ramesh S, Parameswaran A. Polyvinyl siloxane: novel material for external nasal splinting. Inter J Oral Maxillof Surg 2016; 45(1): 57-59.

16. Re M, Paolucci L, Romeo R, Mallardi V. Surgical treatment of nasal septal perforations. Our experience. Acta Otorhinolaryngol Ital 2006; 26(2): 102-109.

17. Farzal Z, Del Signore AG, Zanation AM, et al. A computational fluid dynamics analysis of the effects of size and shape of anterior nasal septal perforations. Rhinol 2019; 57(2): 153-159.

18. Gold M, Boyack I, Caputo N, Pearlman A. Imaging prevalence of nasal septal perforation in an urban population. Clin Imaging. 2017; 43: 80-2. 